\title{
UNUSUAL FORMS OF HEART BLOCK IN INFANCY
}

BY

\author{
AGUSTIN CASTELLANOS, JR., HORACIO DE LA TORRE, LUIS AZÁN, AND JOSÉ M. \\ CALVIÑO
}

From the Department of Cardiology, Hospital de Infancia and Hospital Universitario, Habana, Cuba.*

Received March 8, 1960

Atrio-ventricular block may be either congenital or acquired: of the latter forms, those due to myocarditis and digitalis are the most common (Langendorf and Pick, 1954). However, the different characteristics of this disorder of rhythm in infancy have not been fully described. For instance, it is interesting to note that, in spite of the great frequency with which $P-R$ prolongation can be found in children's routine electrocardiograms (Nadas, 1957), few instances of retrograde heart block or even simple retrograde conduction have been reported in children (Langendorf and Pick, 1954; Nadas, 1957; Keith et al., 1958). On the other hand, whenever the proper technique was used for its detection, ventriculo-atrial conduction has been found in many tracings of adult patients (Kistin and Landowne, 1951).

Furthermore, phenomena affecting the A-V junction, such as the supernormal phase or reciprocal rhythm, which have been known for a long time but have recently been re-emphasized, have seldom been described (Katz and Pick, 1956). It is the purpose of this paper to present several unusual clinical examples of heart block with certain peculiarities that justify its presentation as a separate communication.

\section{Material AND Methods}

Our material consists of three cases, selected from the file of the cardiological department of the Children's Municipal Hospital. All had in common the occurrence of heart block with different characteristics, and in addition they presented various interesting phenomena that are fundamental in understanding the dynamics of atrio-ventricular conduction. The analysis of this propagation was made according to the rules originally set by Sir Thomas Lewis (Lewis and Master, 1925) and later expanded by Besoain-Santander et al. (1950), and by Katz and Pick (1956). For the determination of the $Q-T$ interval, Bazzet's (1920) formula was used $(Q-T c=Q-T / \sqrt{R-R})$. The results obtained were then compared with published tables of normal children, classified according to age (Ziegler, 1951).

\section{COMMENTS}

Some introductory remarks concerning atrio-ventricular (A-V) block, in general, are considered necessary before describing the abnormal records. A-V block is defined as an abnormal prolongation of the refractory phase of the A-V junctional tissues (Katz and Pick, 1956). It can affect the relative phase only (first degree A-V block, Fig. 1), both the relative and the absolute phase (second degree A-V block), or only the absolute phase (complete A-V block). This refers mainly to acquired block, for in the congenital form of the complete variety an interruption of the anatomical pathways is generally present (Campbell and Thorne, 1956).

\footnotetext{
* Studies supported by a grant from the Christian Association for the Welfare of Sick Children.
} 

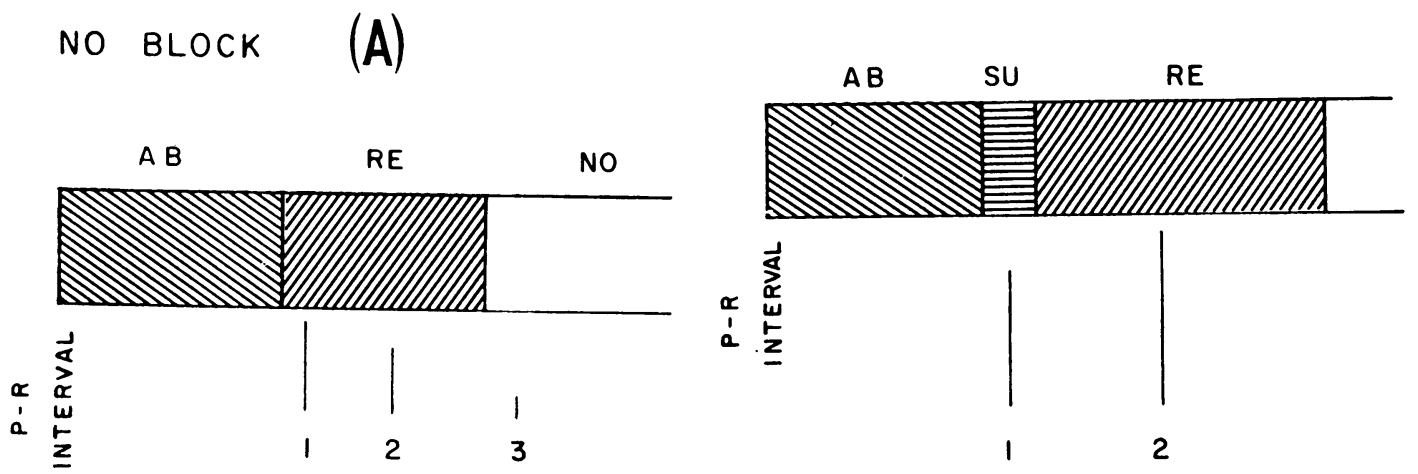

FIG. 1.-Schematic diagrams illustrating the various phases of conductivity of the A-V junction.

AB represents the absolute refractory period, RE the relative refractory period, SU the supernormal phase, and NO the normal period during which conduction takes place at its basic speed for the individual patient. The vertical lines of different length represent the hypothetical duration of the $\mathbf{P}-\mathbf{R}$ interval, the numbers below them representing different atrial stimuli arriving at various parts of the heart cycle $(1,2,3)$. No atrial complex arriving at the A-V junctional tissues during the absolute refractory phase can traverse it, so that those $P$ waves have no corresponding QRS complex. Furthermore, (A) illustrates a third cycle without heart block, a term that by definition implies an abnormal prolongation of the refractory period whether absolute or relative (Castellanos et al., 1958). In this instance, all atrial impulses arriving during the relative phase are conducted with a longer $\mathbf{P}-\mathbf{R}$ interval than those arriving after the end of the latter (1 and 2>3). Moreover, the nearer an impulse to the absolute phase, the longer its P-R distance (1>2). On the other hand, (B) represents a cycle with an abnormal prolongation of the relative phase (first degree A-V block). Consequently, all atrial impulses arriving during that phase are transmitted with a prolonged A-V conduction time. Yet, paradoxically, a supernormal phase has now appeared sandwiched between the absolute and relative periods, and is characterized by the fact that impulses located nearer to absolute refractoriness are conducted with the shorter $\mathbf{P}-\mathbf{R}$ interval than those arriving later $(1<2)$. This is an inverse relationship to that occurring normally and shown in $(A)$.

For didactic purposes the various phases of conductivity of the A-V junction, during normal conduction and during first degree block, can be seen in Fig. 1 and are fully described in the corresponding legend. Furthermore, in Fig. 1B, that unusual phenomenon so rarely encountered in human pathology, the supernormal phase, is presented. It occurs, as stated recently, almost always in cases in which conductivity is depressed and is characterized by enhanced impulse transmission at a time when it can be expected to be impaired (Langendorf, 1958).

\section{The Supernormal Phase of $A-V$ Conduction}

The tracings observed in Fig. 2 were obtained from a 9-year-old girl with acute rheumatic fever after initial digitalization with digoxin ( $2 \mathrm{mg}$. in two doses, 8 hours apart). The $P$ waves, occurring at a regular rate of 150 a minute, are slightly notched, and are different from the sinus $\mathbf{P}$ waves (not shown), so that the fundamental rhythm can be considered to be an atrial tachycardia with first degree A-V block. In both records, a curious form of alternation in the length of the $\mathbf{R}-\mathbf{R}$ cycle appears: a long $\mathrm{R}-\mathrm{R}$ alternates with a short one (all values marked on the tracing). Moreover, a detailed analysis reveals also an alternation of A-V conduction time.

Table I, which represents the values obtained from the lower tracing of Fig. 2, shows how, paradoxically, the shorter R-P intervals are followed by the shorter $\mathbf{P}-\mathbf{R}$; and vice versa, the longer $\mathbf{R}-\mathbf{P}$ intervals are followed by the longer P-R. This finding is the opposite of what happens normally, for then, the shorter the R-P, the longer the P-R interval (Fig. 1A). However, it can be well explained by the existence of a supernormal phase of A-V conduction as postulated and explained in the diagram of Fig. 1B. In other words, conduction is enhanced at a time when it would be expected to be delayed.

No records showing this phenomenon in children have been published (Langendorf and Pick, 1954; Nadas, 1957; Keith et al., 1958), although well-described cases in adult patients have been 


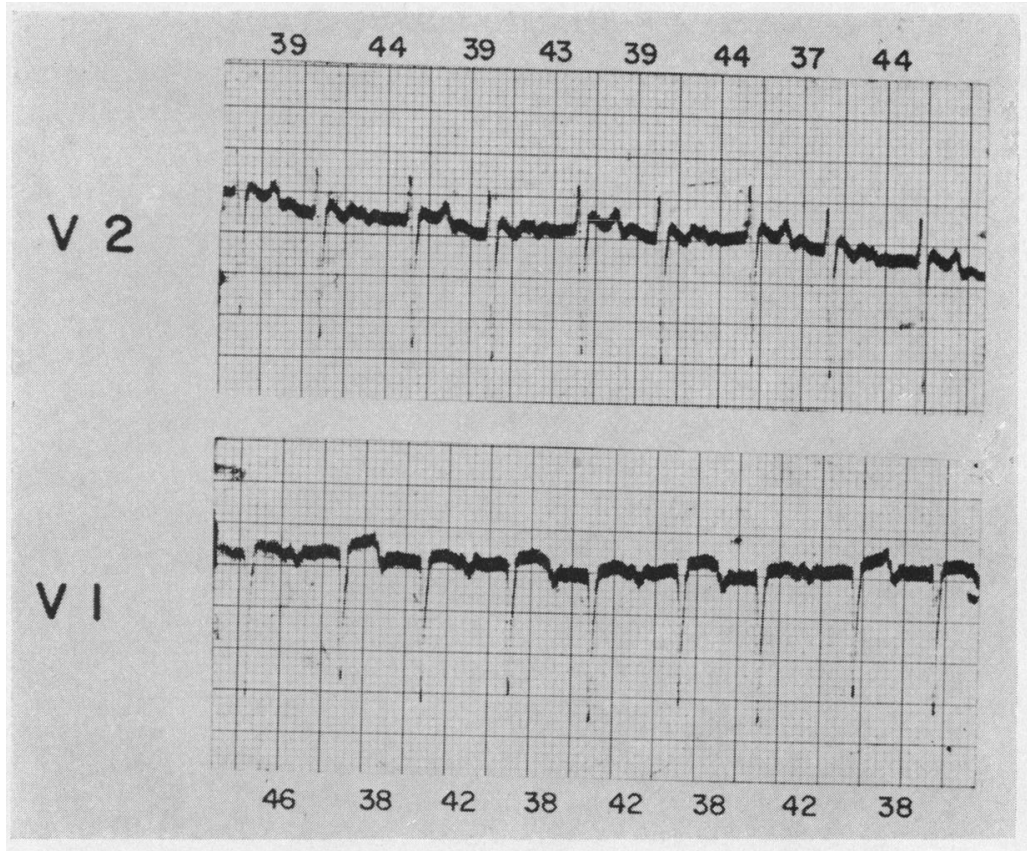

FIG. 2.-Paroxysmal atrial tachycardia with first degree A-V block due to digitalis poisoning. Alternation of A-V conduction time due to the supernormal phase is also present. The shape of the $P$ waves changes because it occurs during different parts of the $T$ waves. All numbers indicate the duration of the $\mathbf{R}-\mathbf{R}$ intervals expressed in hundredths of a second. See text.

TABLE I

Relation Between the R-P Distance and the P-R Interval

\begin{tabular}{cc|cc}
\hline Long R-P & Long P-R & Short R-P & Short P-R \\
\hline 28 & 28 & 22 & 22 \\
28 & 25 & 24 & 20 \\
28 & 25 & 24 & 20 \\
29 & 26 & 24 & 22 \\
\hline
\end{tabular}

Numbers (indicating intervals in hundredths of a second) were obtained from the lower records of Fig. 2.

reported recently (Langendorf, 1958). Yet, this is understandable due to the fact that the arrhythmia is rare in adults also. As a rule, the supernormal phase appears chiefly in digitalized patients, with coexisting depressed conductivity, almost always when first degree A-V block is the fundamental rhythm.

Whenever the atrial rate is only moderately fast, as in this case, clinical auscultation may be misleading due to the irregular ventricular beating. Obviously, the paroxysm can be mistaken for a fast sinus arrhythmia, or perhaps erroneously for ventricular tachycardia, because until recently, the supraventricular ectopic tachycardias have been considered strictly regular, contrasting with the usually irregular ventricular ones (Castellanos et al., 1958).

Finally, the treatment of the disorder of rhythm should be the same as that of all tachycardias due to digitalis poisoning. Prompt withdrawal of the drug, as well as the administration of potassium, is stressed, for continued digitalization can cause increased ryhthmicity of others centres, specifically the appearance of a nodal or ventricular tachycardia (Castellanos et al., 1960). 


\section{2:1 A-V Block due to Hypocalcamia}

Fig. 3 shows the records obtained from a 6-hours-old premature child with cerebral hæmorrhage. The main characteristic in the bipolar leads is a low voltage of the ventricular complexes, accompanied by disseminated artefacts due to occasional bursts of muscle tremor. Inspection of leads II, aVL, V1 (Fig. 3), and V4R (Fig. 4) establishes beyond doubt the presence of a sinus rhythm (rate

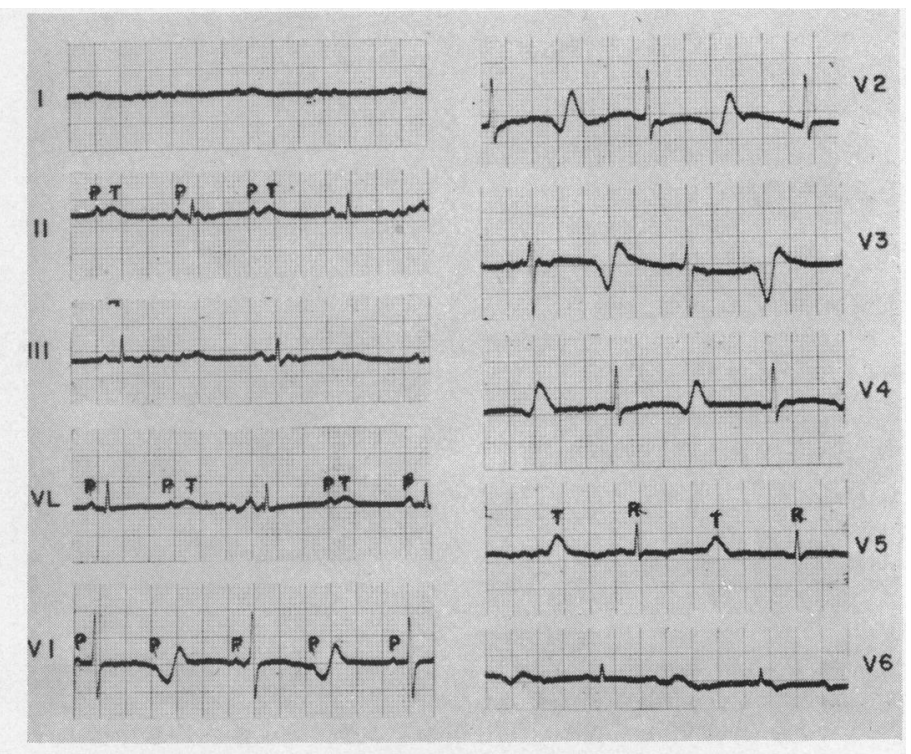

FIG. 3.-Partial 2:1 A-V block due to hypocalcæmia in a 6-hour-old premature infant. The Q-T interval measures $0.65 \mathrm{sec}$. Such a prolonged duration (which is seldom encountered) explains perfectly the genesis of the 2:1 A-V block (see Fig. 5). See text.

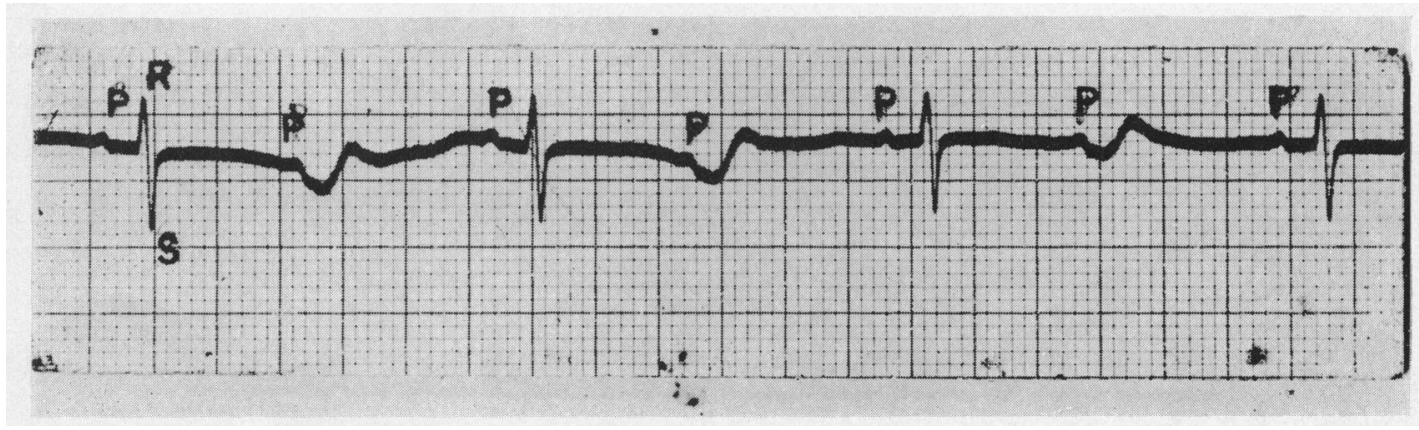

FIG. 4.-Same patient as in Fig. 3. The chest lead (V4R) was enlarged to show the blocked $\mathbf{P}$ wave falling before a diphasic $(-+) \mathrm{T}$ wave, which, in turn, appears at the end of a prolonged isoelectric $\mathrm{S}-\mathrm{T}$ interval.

97 a minute) with $2: 1 \mathrm{~A}-\mathrm{V}$ block, the $\mathrm{P}-\mathrm{R}$ of the conducted beat measuring $0 \cdot 14 \mathrm{sec}$. Note that the blocked $P$ waves fall before the end of the $T$ wave. Also in leads V4R, V1, V2, V3, and V4, a curious $\mathrm{T}$ wave can be seen with an unusual shape, for it is diphasic $(-+)$ with a large, pointed, terminal part, and located at the end of a prolonged, isoelectric, S-T interval. Originally, it was thought that this bizarre complex was a ventricular extrasystole, but the normal shape of the $\mathrm{T}$ in leads II and aVL disproves such consideration. As a result, when Bazzet's formula for the calculation of the Q-T interval was applied, a value of $0.65 \mathrm{sec}$. was obtained, which exceeds the upper limit set for normal newborn children (Ziegler, 1951). 
Clinical examination of this patient showed signs of hypocalcæmia, which were confirmed by the finding of a plasma calcium of $2 \cdot 7 \mathrm{mEq} / 1$. However, potassium was normal $(4 \cdot 2 \mathrm{mEq} / 1$. $)$. Unfortunately, the child died a few minutes later, before an appropriate correction of hypocalcæmia could be performed.

Some of the electrocardiographic findings of this patient could be explained on the basis of low calcium and normal potassium. For instance, the prolonged Q-T interval is a main feature of hypocalcæmia (although such a high value is very infrequent) and is in agreement with the experimental work of Brooks et al. (1955), who found that the plateau characteristic of the action potential was increased, without altering the rate of terminal repolarization, when the calcium concentration of the preparation was well below normal. However, in this patient the $\mathrm{T}$ wave presents such an unusual shape, that another factor (not hypocalcæmia) had to account for the disturbed terminal phase of repolarization. Probably, myocardial damage could be this factor, because serum potassium was normal, and this was the other cause that could have produced peaked $\mathrm{T}$ waves in some leads.

As a consequence of the prolonged electrical systole, absolute refractoriness of the ventricular, as well of the specialized, fibres was greatly increased. Due to this fact, the rhythmically incoming atrial impulse would be alternatively blocked. A diagram of this situation is shown in Fig. 5,
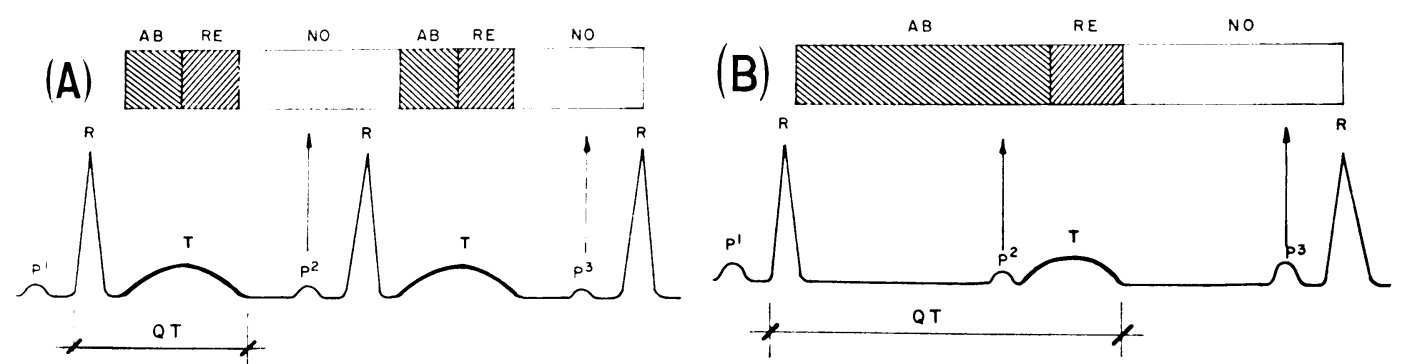

Fig. 5.-Diagrams of 2:1 A-V block due to hypocalcæmia.

$A B$ represents the absolute refractory period of the A-V junction; RE, the relative refractory period; NO, the normal period of time during which $A-V$ conduction takes place at its basic speed for this patient. In both parts the various phases have been related to the electrocardiogram.

In (A) it can be seen that $\mathrm{P} 2$ and $\mathrm{P} 3$ arrive at the $\mathrm{A}-\mathrm{V}$ junction during NO, when conduction can take place at the basic speed for this patient. Consequently, the $P-R$ interval is normal.

In (B) the Q-T interval is prolonged due to hypocalcæmia and the T wave, not necessarily altered, can be seen towards the end of such a prolonged $Q-T$ interval. Hence, the absolute refractory phase (AB) of the A-V intermediate tissues is generally increased. Furthermore, the rhythmically produced P2 arrives at the A-V junction at its usual time, but finds these tissues absolutely refractory, so that its conduction towards the ventricles is "blocked". Finally, P3 arrives at the A-V junction at a time favourable for normal conduction (after the end of the refractory period), so that the $\mathrm{P}-\mathrm{R}$ interval is normal.

which accurately reproduces the conditions present in Fig. 3 and 4 . Accordingly, there is no doubt that the 2:1 A-V block can be ascribed to hypocalcæmia, so that another cause of heart block in children is postulated in this communication, and can be added to the previously known ones. Finally, another fact has to be emphasized. A very high concentration of calcium can prolong the $\mathrm{P}-\mathrm{R}$ interval without affecting or even shortening the $\mathrm{Q}-\mathrm{T}$ interval (Brooks et al., 1955). In these experiments the prolongation of $\mathrm{A}-\mathrm{V}$ conduction time was caused specifically by affecting conductivity and by an augmented vagal tone, and not by an increased refractoriness of the cardiac tissues.

\section{Wandering Pacemaker in the A-V Node, Retrograde Heart Block, Wenckebach Phenomenon of Retrograde Conduction, and Reciprocal Beats with Aberration}

The records in Fig. 6 were taken from a non-digitalized girl, aged 5, with a persistent atrioventricular canal. The first two complexes of the upper row originate in the upper part of the $\mathrm{A}-\mathrm{V}$ node. As the corresponding $\mathrm{P}-\mathrm{R}$ intervals are prolonged, first degree $\mathrm{A}-\mathrm{V}$ block has to be 


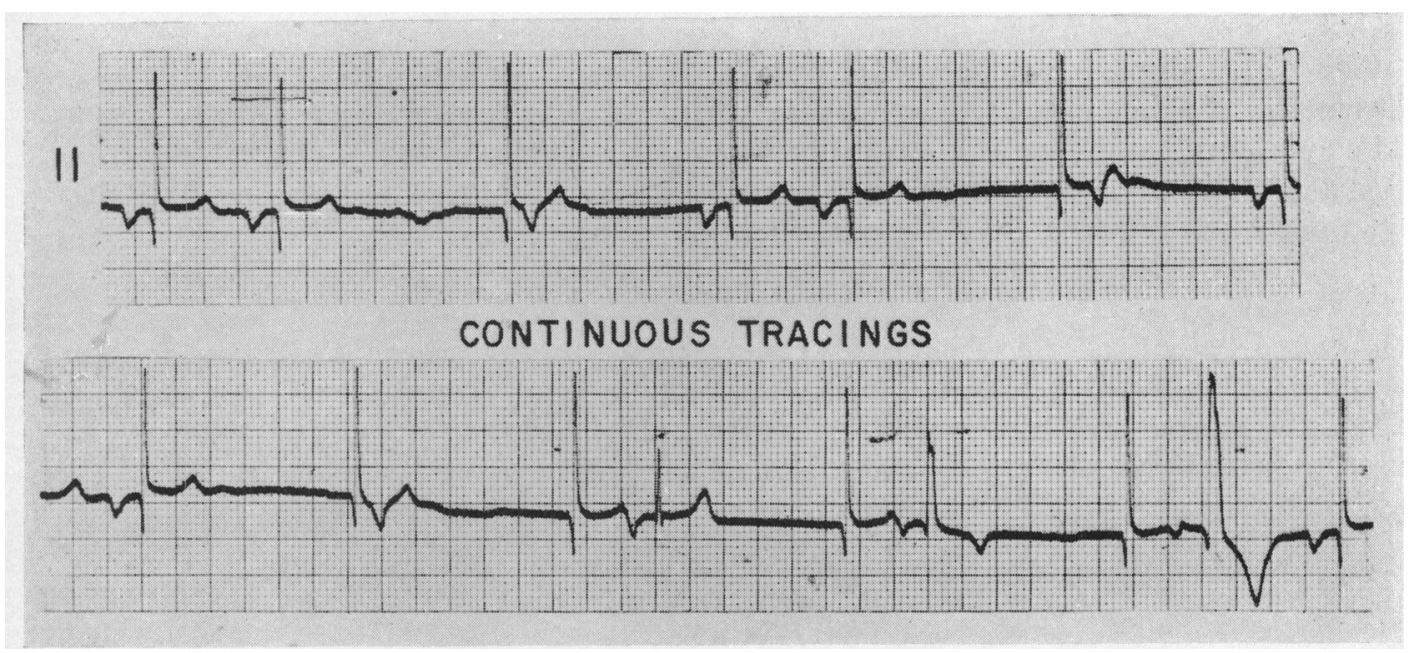

FIG. 6.-Wandering pacemaker in the A-V node, retrograde heart block with the Wenckebach phenomenon of retrograde conduction, reciprocal rhythm, and aberration of reciprocal beats. See text.

added. Subsequently, after a long pause of $1.34 \mathrm{sec}$., the pacemaker shifts to the lower A-V regions, but now the R-P measures $0 \cdot 12 \mathrm{sec}$. (retrograde heart block). Then the cycle starts anew, for two upper nodal beats are seen, preceding a pause of $1.22 \mathrm{sec}$, which in turn comes before a lower A-V beat whose R-P measures $\mathbf{0 . 2 6} \mathrm{sec}$. Again, the first ventricular complex of the lower row presents a $P-R$ interval of $0.18 \mathrm{sec}$, and it precedes another complex with an $R-P$ of $0.20 \mathrm{sec}$. This distance is increased to $0.39 \mathrm{sec}$. in the third nodal beat. Such a progressive increase of ventriculo-atrial conduction is due to the Wenckebach phenomenon. Furthermore, when retrograde conduction takes so much time $(0.39 \mathrm{sec}$.) the conditions are opportune for the nodal impulse to re-enter the A-V junction and produce a premature (reciprocal) beat. In fact, this stimulus in its way back to the atria finds responsive tissues, being able to change its direction and stimulate again the ventricles (fourth, sixth, and eighth QRS complexes). As stated by Katz and Pick (1956), the occurrence of such a re-entry is favoured by the slow retrograde spread of the original impulse and takes place in the syncytium within the A-V node, and not in the atria. Besides, another finding of interest is the abnormal shape of the re-entry complexes. This is due to prematurity of the returning excitation, which finds the bundle branches still refractory, so that the intra-ventricular conduction is aberrant. Reciprocal rhythm occurs after the third, fifth, and seventh lower nodal beats, and then the tracing ends with the pacemaker shifting again to the upper regions of the node.

It is our impression that this arrhythmia cannot be attributed to the anatomical defect, per se. Although it is known that the P-R prolongation is a frequent finding in cases with ostium A-V communis, no instance of retrograde block has been reported in this malformation (Toscano Barbosa et al., 1956). On the other hand, sinus rhythm was not seen in any of the thirteen records taken from this girl during a three-year period-a phenomenon that led us to believe we might perhaps be dealing with a case of congenital absence of the sinus node. Contrasting with the great frequency of forward heart block, retrograde heart block has seldom been described. It is not even mentioned in two recently published text-books dealing with pediatric cardiology (Nadas, 1957; Keith et al., 1958). It seems that there is only one published report (Sodi-Pallares et al., 1959), but this case was discussed on the basis of an A-V nodal rhythm existing in a 9-year-old girl with dextrocardia: undoubtedly, their Fig. 9 reveals an infra-nodal rhythm with reciprocal beats.

Moreover, the occurrence of ventricular tachycardia with retrograde conduction is seldom encountered, but it should be remembered that this arrhythmia is very infrequent at an early age. Many paroxysms of rapid heart action with widened QRS complexes are of supraventricular and not of ventricular origin (Castellanos et al., 1958). 
If we add to this, that œsophageal leads are sometimes necessary to diagnose correctly retrograde conduction (on account of the poor visualization of the negative $P$ wave in the conventional leads (Kistin and Landowne, 1951)), then the possibilities of finding V-A conduction are very small. In spite of this assumption, one case in which a disorder of rhythm of this kind could be seen in the standard leads has been presented (Langendorf and Pick, 1954).

Lastly, the rarity of passive A-V nodal rhythms with V-A response can be attributed to the infrequency of such slow rhythms. As a rule, digitalis or any form of myocarditis hardly ever decreases the rate of the A-V node in children-an anatomical structure that has a great tendency to enhance rhythmicity. Evidence of this is the relatively high rate of the nodal pacemaker in congenital complete A-V block, when it is compared with that of adults (Campbell and Thorne, 1956).

\section{SUMMARY}

Various selected electrocardiograms have been presented to illustrate heart block with unusual characteristics in children. Initially, the physiology of the A-V junction is described, with special reference to the various phases of A-V conduction.

Subsequently, the following arrhythmias are presented: (a) the supernormal phase, (b) $2: 1 \mathrm{~A}-\mathrm{V}$ block due to hypocalcæmia, and (c) retrograde heart block, the Wenckebach phenomenon of retrograde conduction, and reciprocal beats with aberration. Explanations of their electrocardiographic significance are discussed, as well as possible causes for the infrequency with which these disorders of rhythm occur in children.

\section{REFERENCES}

Bazzet, H. C. (1920). Heart, 7, 353.

Besoain-Santander, M., Pick, A., and Langendorf, R. (1950). Circulation, $2,604$.

Brooks, C. Mc., Hoffman, B., Suckling, E. E., and Arias, O. (1955). Excitability of the Heart. Grune and Stratton, New York.

Campbell, M., and Thorne, M. G. (1956). Brit. Heart J., 18, 90.

Castellanos, A., Calviño, J. M., Azán, L., and Castellanos, A., Jr. (1958). J. Pediat., 55, 285.

Castellanos, A., Jr., Calviño, J. M., and Azán, L. (1960). Amer. Heart J., 59, 358.

Katz, L. N., and Pick, A. (1956). Clinical Electrocardiography, Part I, The Arrhythmias. Lea and Fibiger, Philadelphia.

Keith, J. D., Rowe, R. D., and Vlad, P. (1958). Heart Disease in Infancy and Childhood. Macmillan, New York.

Kistin, A. D., and Landowne, M. (1951). Circulation, 3, 738.

Langendorf, R., (1958). Amer. Heart J., 55, 181.

, and Pick, A. (1954). Ped. Clin. North Amer., 1, 215.

Lewis, T., and Master, A. (1925). Heart, 12, 209.

Nadas, A. (1957). Pediatric Cardiology. Saunders, Philadelphia.

Sodi-Pallares, D., Bisteni, A., Fishleder, B., and Medrano, G. (1959). Amer. Heart J., 57, 590.

Toscano-Barbosa, E., Brandenburg, R. O., and Burchell, H. B. (1956). Proc. Mayo Clin., 31, 513.

Ziegler, R. F. (1951), Electrocardiographic Studies in Normal Infants and Children. Thomas, Springfield. 